\title{
Development and Performance Evaluation of Palm Kernel Shells Fueled Stove Converting Waste to Energy
}

\author{
Basil Olufemi Akinnuli¹, Oluwaseun Oluwagbemiga 0jo², Olutosin Olufisayo Ilori² \\ ${ }^{1}$ Federal University of Technology, Akure, Nigeria \\ ${ }^{2}$ Adeleke University, Ede, Nigeria \\ Email: ojo.oluwaseun@adelekeuniversity.edu.ng
}

How to cite this paper: Akinnuli, B.O., Ojo, O.O. and Ilori, O.O. (2018) Development and Performance Evaluation of Palm Kernel Shells Fueled Stove Converting Waste to Energy. Open Access Library Journal, 5: e5032.

https://doi.org/10.4236/oalib.1105032

Received: November 5, 2018

Accepted: December 18, 2018

Published: December 21, 2018

Copyright $\odot 2018$ by authors and Open Access Library Inc.

This work is licensed under the Creative Commons Attribution International License (CC BY 4.0).

http://creativecommons.org/licenses/by/4.0/

\begin{abstract}
Oil palm (Elaesis guineensis Jacq.) is an indigenous forest product of West Africa. The natural groves usually have palms that bear ordinary fruits. These fruits emerged hard-kernelled shell (dura) and thin-kernelled shell (tenera). These kernels were found useful as fuel by researcher due to its high calorific value. The existing fuels such as kerosene, gas, are out of reach to an average Nigerian due to its scarcity and high cost. Other means of fuels like charcoal, wood are not hygienic and also not easy to get due to high rate of deforestation, hence the development of kernel-fuel stove. This was possible after preliminary investigation of its calorific value which was found to be $16.9 \mathrm{MJ}$. The major components of the kernel-fueled stove are the: frame, blower, miner plate, pot carrier and burning chamber. The capacity of the stove is $22.4 \mathrm{~kg}$ of kernel shell; its performance evaluation was carried out by comparing the developed stove with other stoves fueled by sawdust, charcoal, gas, kerosene and electric cooker, and it was discovered it got the shortest time for boiling 3 liters of water in 2.30 minutes.
\end{abstract}

\section{Subject Areas \\ Bioengineering \\ Keywords \\ Performance Evaluation, Palm Kernel, Stove Development, Calorific Value, Fuel}

\section{Introduction}

In Nigeria, agriculture has remained one of the important sectors of the econ- 
omy. It generates employment for about seventy percent of Nigeria's population and contributes about forty percent of the gross domestic product (GDP) with crops production accounting for eighty percent, livestock thirteen percent, and fisheries four percent [1] [2]. The Council for Renewable Energy of Nigeria (CREW) estimates that power outage brought about a loss of 126 billion NGN (984.38 Million USD) annually [3] [4]. The predominant energy resources for domestic and commercial uses in Nigeria are fuel, wood, charcoal, palm kernel shell, palm fibre, kerosene, cooking gas and electricity [5]. Other sources, though less common, are sawdust, agricultural crop residue of cornstalk, cassava stick, and in extreme cases, cow dung.

Development and utilization of renewable energy should be given a high priority especially in the lights of increased awareness of the adverse environment impact of fossil and based generation. The need for sustainable energy is rapidly increasing in the world. A wide spread use of renewable energy is important for achieving sustainability in the energy sector in both developing and industrialized countries [6] [7].

[8] studied combustion characteristic of palm kernel using an inclined grate combustor. The inclined grate fixed bed combustion chamber used to burn the palm shell exhibits low capability with conversion rate of twenty percent to thirty two percent of its calorific value. Main design faults were identified for the combustion-air distribution system as well as fuel and distribution. [9] [10] conducted a review on electricity generation based on biomass residue in Malaysia.

[11] performed economic analysis of diesel-fuel replacement by crude palm oil in Indonesian power plants. Their analysis was basically on the needs to find an alternative fuel to substitute diesel in their power plants in order to reduce the use of non-renewable energy sources in Indonesia.

[12] studied progress and challenges in utilization of palm oil biomass as fuel for decentralized electricity. His findings revealed that generating electricity such as biomass power would help transform the entire economic activity and large part of rural population would be able to use the energy for various basic needs. [13] [14] compared the combustion efficiency of palm waste such as palm fibre, palm kernel shell (PKS) and empty fruit bunches in a fluidized bed and spouted bed. The result showed that for combustion of palm fibre and palm kernel shell, the fluidized bed has higher combustion efficiency compared to spouted bed.

[15] [16] presented a comprehensive review of biomass resources and biofuel production potential in Nigeria. The review shows that a variety of biomass resources exist in Nigeria and that there is also immense opportunity for their conversions for various types of biofuel using different biomass conversion technologies that are currently available.

Stove is an enclosed space in which fuel is burned to provide heating, either to heat the space in which the stove is situated, or to heat the stove itself and the item placed on it. Table 1 shows the summary of available stoves with their pictures, description, efficiency and price range where available. 
Table 1. Overview of current available stove, [17].

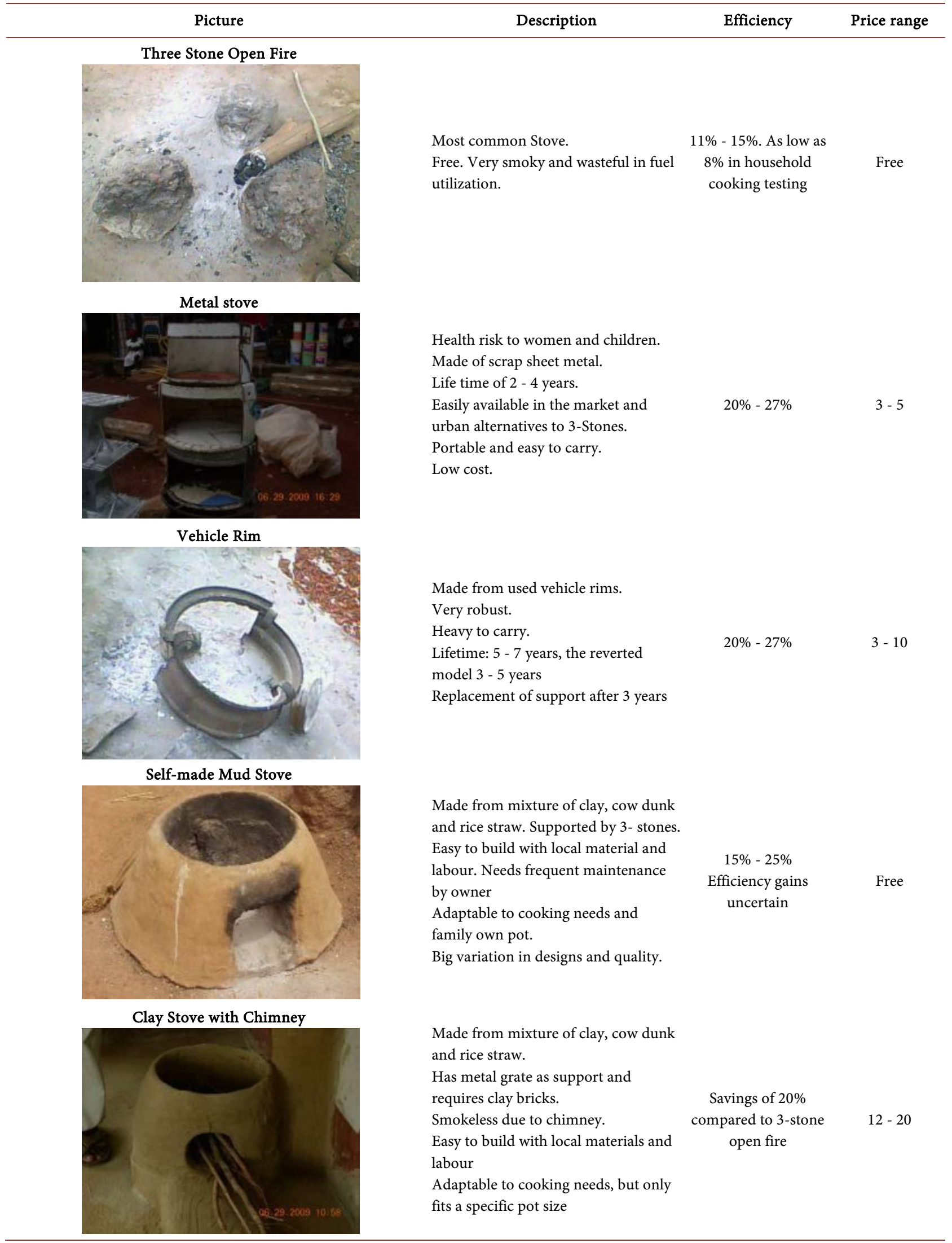




\section{Continued}

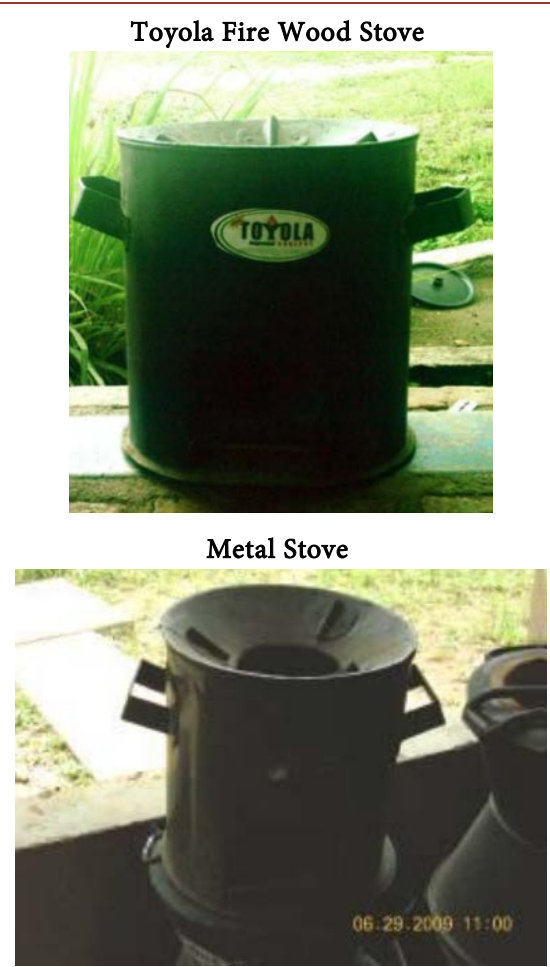

Envirofit B-1100

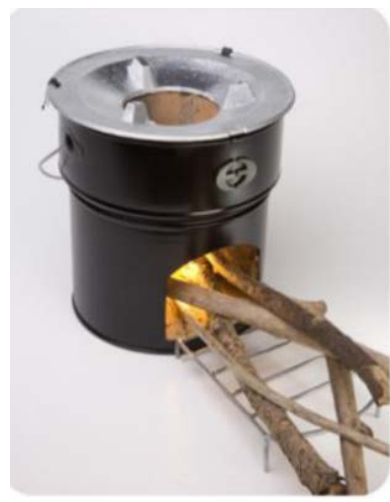

Philips Smokeless Stove.

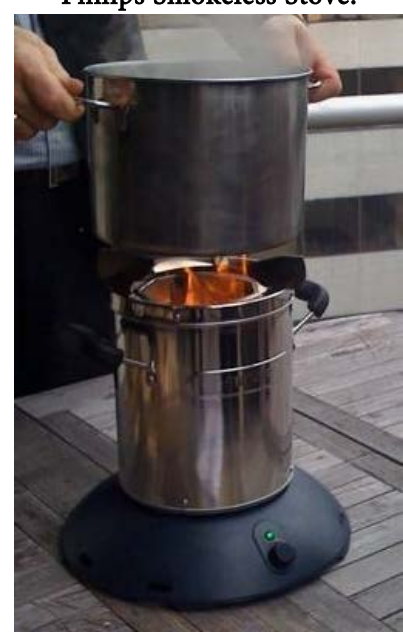

Made of scrap metal with ceramic

liner.

Requires high degree of ceramic expertise, quality clay and assess to kiln.

Portable.

Liner can also be used for fixed or portable clay stoves and are built into e.g. larger multi pot institutional stoves

Made up of sheet metal

Not yet in circulation but is tested in Northern Ghana by the NGO, New Energy

Need for laboratory and field test.

Can also be used with saw dust

Industrial improved firewood stove Lunched in India but on its way to several African countries.

Envirofit is an NGO based in

Colorado, US. Development

supported by the shell foundation and

Colorado State University.

Portable, all biomass types can be used.

Produced in China

Industrialized improved firewood

Stove.

Lunched in India by Philips in 2008

for a trial. Electronically controlled fan

forces air through the stove leading to better fuel to air ratio.

Savings Up to $80 \%$

N.a.

Usable for small pieces of wood. Very

low fuel consumption.

Smoke free and portable.

Produced in China.

Cost from

10 - 20 USD

(from $500-100$ Indian rupees) 
In order to determine which type of heating fuel is the best value, four different variables were considered in literature which are: the type of heating fuels (solid, liquid, electricity, or gas); the unit cost of heating fuels (amount of money cost by unit measure); per unit content of fuel (measured in Btu's); and annual fuel utilization efficiency (AFUE).

Table 2 shows the demerits in the existing stoves.

Table 3 demonstrates the different types of fuels used by stoves and their comparison of entropy constant.

\section{Methodology}

The method used in this research covered: identification of required components of the proposed stove design, analysis of each component, components material selection, engineering drawing of the stove, components' production and their assembly, test of the stove and comparison with the existing ones to evaluate its performance.

Components: the components are pot holder, air inlet plate, centrifugal fan, outlet plate, top plate and the frame.

Table 2. Different types of stoves and their demerits.

\begin{tabular}{|c|c|c|}
\hline $\mathrm{S} / \mathrm{N}$ & Stove & Demerit(s) \\
\hline 1 & $\begin{array}{c}\text { Kerosene } \\
\text { Stove }\end{array}$ & $\begin{array}{l}\text { 1) High fuel cost } \\
\text { 2) Ventilation required } \\
\text { 3) Spillage of fuel that can cause fire } \\
\text { 4) Burn risk is possible }\end{array}$ \\
\hline 2 & $\begin{array}{l}\text { Firewood } \\
\text { Stove }\end{array}$ & $\begin{array}{l}\text { 1) Large quantity of firewood is required } \\
\text { 2) Cooks food slowly } \\
\text { 3) Gather smoke in the kitchen } \\
\text { 4) Makes the kitchen utensils dirty } \\
\text { 5) Makes pot black with sooth } \\
\text { 6) Smokes from wood may be life threatening }\end{array}$ \\
\hline 3 & $\begin{array}{c}\text { Natural Gas } \\
\text { Stove }\end{array}$ & $\begin{array}{l}\text { 1) Expensive to buy and install } \\
\text { 2) Dangerous due to the possibility of gas leakages } \\
\text { 3) Give off humid heat rather than the dry heat required for effective roasting } \\
\text { 4) Gas leaks cause rooms and building to be filled with toxic, flammable gas }\end{array}$ \\
\hline 4 & $\begin{array}{l}\text { Electric } \\
\text { Stove }\end{array}$ & $\begin{array}{l}\text { 1) Coils take longer time to heat up, which can slow down cooking process } \\
\text { 2) Heat from stove tends to radiate through the entire kitchen which can make } \\
\text { it uncomfortable to cook at times } \\
\text { 3) There is need for constant supply of electricity } \\
\text { 4) Cost of operating it is very high }\end{array}$ \\
\hline 5 & $\begin{array}{l}\text { Propane } \\
\text { Stove }\end{array}$ & $\begin{array}{l}\text { 1) Produced instant heat, but sometimes produces offensive odour } \\
\text { 2) Frequently has been causing carbon monoxide poisoning when used indoor } \\
\text { or poorly ventilated areas } \\
\text { 3) Denser than air, if a leak in propan fuel occurs, the gas will have a tendency } \\
\text { to sink into any enclosed area and thus poses a risk of explosion and fire }\end{array}$ \\
\hline 6 & $\begin{array}{c}\text { Anthracite } \\
\text { Coal }\end{array}$ & $\begin{array}{l}\text { 1) Dirty } \\
\text { 2) More attention to fire and furnace is necessary } \\
\text { 3) Heat in fuel is difficult to realize } \\
\text { 4) Like all fossil fuels, burning anthracite coal emits deadly carbon monoxides } \\
\text { therefore a good chimney is a necessity }\end{array}$ \\
\hline
\end{tabular}


Table 3. Different types of fuels used by stoves and comparison of entropy constant.

\begin{tabular}{ccc}
\hline Types & BTU/Unit & Kilocalories/Unit \\
\hline Kerosene (No 1 fuel oil) & $134,000 /$ gallon & $8921 /$ liter \\
Burner fuel oil (No 2 oil) & $140,000 /$ gallon & $9320 /$ liter \\
Electricity & $3413 / \mathrm{kWh}$ & $860 / \mathrm{kWh}$ \\
Natural gas & $1,000,000 /$ thousand cord & 7139 cubic meter \\
Propane & $91,600 /$ gallon & $6098 /$ liter \\
Anthracite coal & $27,800,000 /$ ton & $6,354,286 /$ tonne \\
Hardwood (20\% moisture) & $24,000 /$ cord & $1,687,500 /$ cubic meter \\
Pine (20\% moisture) & $18,000 /$ cord & $1,265,625 /$ cubic meter \\
Wood pellets (pellet stoves) & $36,000,000$ & $8,228,572 /$ tonne \\
\hline
\end{tabular}

\section{Design Analysis of the Component}

\section{1) Design Analysis of the Frame Support}

The PKS stove was designed for maximum strength load it can carry.

Mass of water and the pot used is $45 \mathrm{~kg}(4.413 \mathrm{KN})$;

Length $(L)$ of the full cross bar $=860 \mathrm{~mm}$;

Load is to be uniformly distributed over the support.

Support reaction

$$
R_{A}=R_{B}=\frac{w l}{2}=2.207 \mathrm{KN} / \mathrm{m}
$$

The shear force $S_{x}$ at section

$$
S_{x}=\frac{w l}{2}-W_{x}
$$

The maximum shear force $S_{x(\max )}$

$$
S_{x(\max )}=S \cdot F=\frac{W L}{2}=1.90 \mathrm{KN}
$$

The maximum bending moment $\left(B_{m}\right)$ of the support

$$
B_{m}=\frac{w l}{2} \times \frac{1}{2}-\frac{w}{2} \times\left(\frac{1}{2}\right)^{2}
$$

$B_{m}=0.41 \mathrm{KNm}$.

Design Analysis of the Fuel Chamber

$$
\text { Volume }(V)=\pi r^{2} h
$$

$V=0.04 \mathrm{~m}^{3}$.

Mass density of palm kernel shell $=560 \mathrm{~kg} / \mathrm{m}^{3}$;

Calorific value of palm kernel shell $=16.9 \mathrm{MJ} / \mathrm{kg}$.

Therefore, the mass of fuel in the stove $=$ mass density of palm kernel shell $\times$ volume of the fuel chamber

$$
F_{m}=f_{d} \times C_{v}
$$

$$
=22.4 \mathrm{~kg}
$$




$$
\text { Available energy }\left(E_{a v}\right)=C_{v} \times F_{m}
$$

$$
=378.6 \mathrm{MJ}
$$

\section{2) Design Analysis of the Blower}

a) Propeller Fan Design

The design power $(P)$ of the fan is $100 \mathrm{~W}$ while working under a head $(H)$ of $600 \mathrm{~m}$ at running speed, $N$ of $2000 \mathrm{rpm}$.

Diameter of impeller $(d)$ is $0.03 \mathrm{~m}$;

Blade thickness at the inlet $\left(b_{1}\right)$ is $40 \mathrm{~mm}$;

Blade thickness at the outlet $\left(b_{2}\right)$ is $15 \mathrm{~mm}$;

Inlet blade angle $\left(\beta_{1}\right)$ is $22.5^{\circ}$;

Outlet blade angle $\left(\beta_{2}\right)$ is $50^{\circ}$;

Mass density of air $\left(\gamma_{a}\right)$ is $1.0 \mathrm{~kg} / \mathrm{m}$.

Figure 1 demonstrates the inlet and outlet velocity diagram.

Blade velocity at inlet $V_{\mathrm{b} 1}$

$$
V_{b 1}=\frac{\pi D_{1} N}{60}
$$

where $D_{1}$ is inlet diameter and $N$ is fan speed in revolutions per minute $V_{\mathrm{b} 1}=$ $1.591 \mathrm{~m} / \mathrm{s}$.

Blade velocity at outlet $V_{\mathrm{b} 2}$

$$
V_{b 2}=\frac{\pi D_{2} N}{60}
$$

$V_{b 2}=3.142 \mathrm{~m} / \mathrm{s}$.

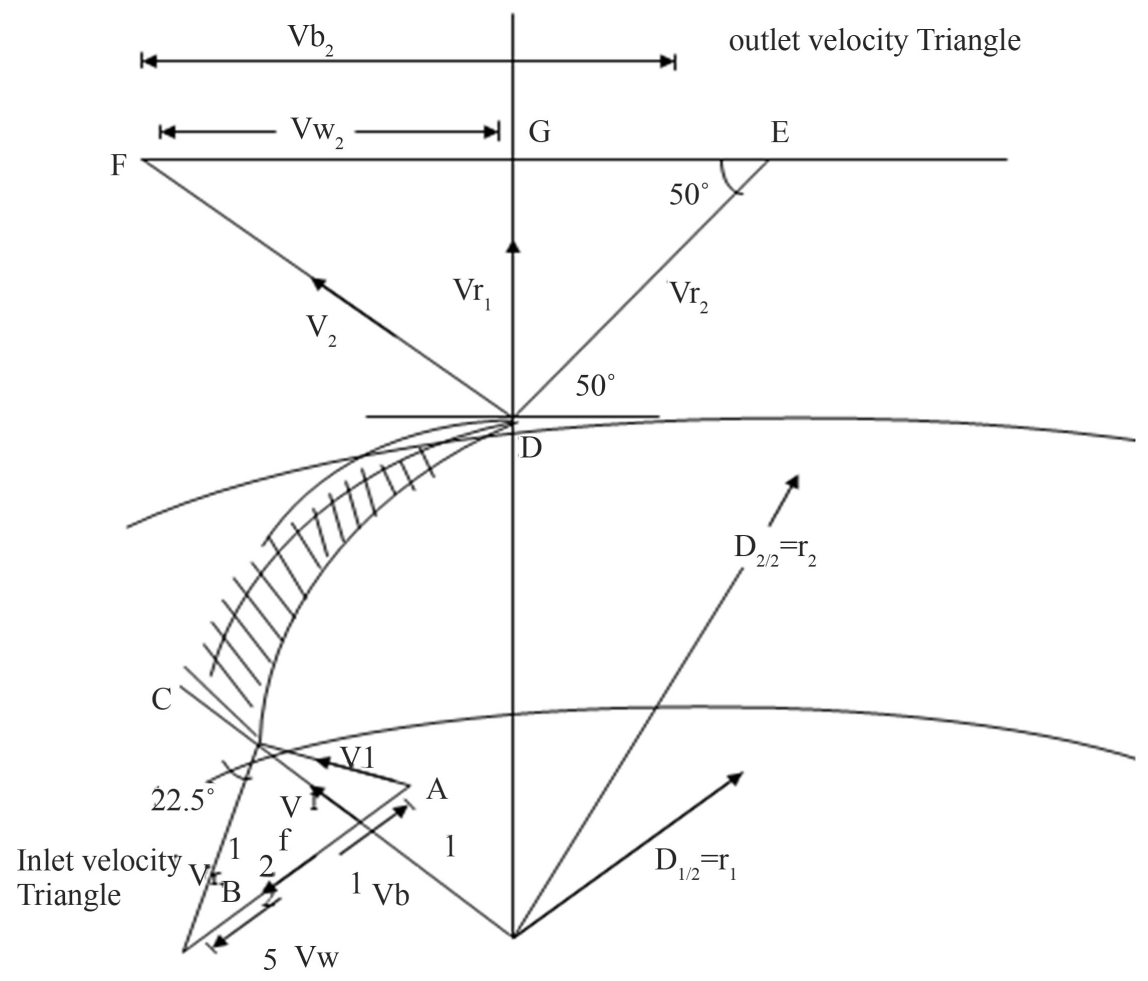

Figure 1. The inlet and outlet velocity diagram. 
b) Quantity of Air Delivered $(Q)$

$$
Q=\pi D_{1} b_{1} V_{f 1}=\pi D_{2} b_{2} V_{f 2}
$$

But velocity of flow at inlet $V_{f}$ is expressed as

$$
V_{f 1}=\frac{Q}{\pi D_{1} b_{1}}
$$

The $Q$ i.e. the required discharge to produce power

$$
Q=\frac{P}{\rho g H}
$$

$Q=0.034 \mathrm{~m}^{3} / \mathrm{s}$.

Hence, $V_{f 1}=18.02 \mathrm{~m} / \mathrm{s}$ [velocity of flow remains constant throughout the runner i.e. $\left.V_{f 1}=V_{f 2}\right]$

The flow rate $\tau$ is given by the ratio of the velocity of flow at the inlet to the theoretical velocity

$$
\tau=\sqrt{2 g H}
$$

$\tau=5.25 \mathrm{~m} / \mathrm{s}$.

The speed ratio $\varnothing$ is given by the ratio of the blade velocity at the inlet $V_{b 1}$ to the theoretical velocity

$$
\varnothing=\frac{V_{b 1}}{\sqrt{2 g H}}
$$

$\varnothing=0.5$

Table 4 explains the ultimate analysis of palm kernel shell.

c) Determination of the Quantity of Heat Released

Figure 2 shows a solid cylinder of radius $r$, insulated with an insulation thickness $\left(r_{2}-r_{1}\right)$.

Where $L$ is length of the cylinder, $T_{1}$ is the surface temperature of the cylinder; $T_{\text {air }}$ is temperature of air; $h_{o}$ is heat transfer coefficient at the outer surface of the insulation and $K$ is thermal conductivity of the insulating material.

The rate of heat transfer from the surface of the solid cylinder to the surrounding is given by

$$
Q=\frac{2 \pi L\left(T_{1}-T_{\text {air }}\right)}{\frac{\ln \left(r_{2} / r_{1}\right)}{K}+\frac{1}{h_{o} r_{2}}}
$$

$Q=39.2 \mathrm{~W} / \mathrm{m}$.

$$
Q_{i}(\text { without insulation })=h_{o} \times 2 \pi r_{1}\left(T_{1}-T_{2}\right)
$$

$Q_{i}=22.6 \mathrm{~W} / \mathrm{m}$.

d) Minimum Insulation Thickness $\left(T_{m}\right)$

$$
T_{m}=r_{c}-r_{1}
$$

where $T_{m}$ is minimum insulation thickness, $r_{c}$ is critical radius of insulation, and $r_{1}$ is radius of the fuel chamber. 
Table 4. Ultimate analysis of palm kernel shell.

\begin{tabular}{cc}
\hline Element & \% of constituent \\
\hline Carbon & 57.01 \\
Oxygen & 31.8 \\
Nitrogen & 0.5 \\
Hydrogen & 11.11 \\
\hline
\end{tabular}

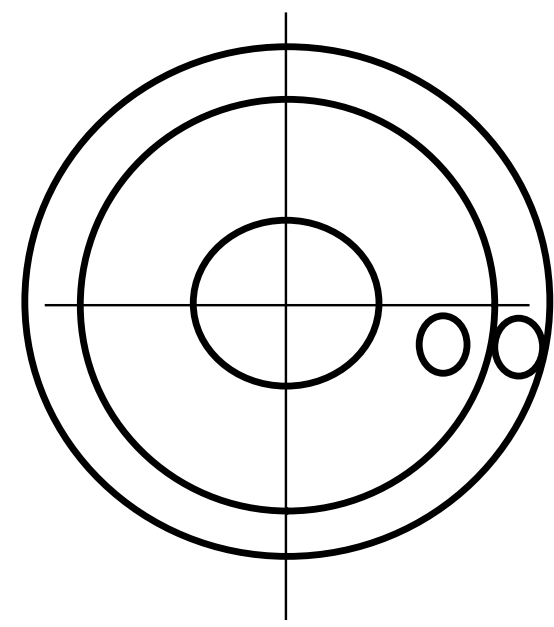

Figure 2. An insulated solid cylinder.

Note $r_{c}=k / h_{o}, T_{m}=0.644 \mathrm{~mm}$.

e) Percentage Increase in Head Dissipation $\left(H_{d}\right)$

$$
H_{d}=\frac{Q_{2}-Q_{1}}{Q_{1}} \times 100
$$

$H_{d}=73.5 \%$.

The required drawing to this developed stove is found in the Appendix.

\section{3) Developed PKS stove Performance Evaluation}

The palm kernel shell stove performance is evaluated by observing its efficiency in cooking relative to other forms of heat source using a stop watch for time taken. Other materials used are thermometer, aluminum pots, sawdust stove, charcoal stove, electric stove, gas cooker, kerosene stove and the PKS stove.

Procedure

a) 3 litres of water are measured into the pot.

b) Light up the stove and allow proper combustion to circulate round before placing the water pot carrying the 3 litres of water with thermometer on the fire.

c) Watch and record the time required for water to attain its boiling point.

d) Repeat the same action on the remaining five sources of heat.

\section{Results and Discussion}

The palm kernel shell stove has been successfully developed having frame of 
shear force of $1.90 \mathrm{KN}$, maximum bending moment of $0.41 \mathrm{KNm}$, fuel chamber of $0.04 \mathrm{~m}^{3}$ and available energy of $378.6 \mathrm{MJ}$ with the blower capable of delivering $0.034 \mathrm{~m}^{3} / \mathrm{s}$ of air. The rate of heat transfer from the surface when insulated to the surrounding is $22.6 \mathrm{w} / \mathrm{m}$ having a minimum insulating thickness of $0.644 \mathrm{~mm}$ while the percentage increase in dissipation is $73.5 \%$.

Evaluating the performance of the stove compared with the other five types of different source of fuel (gas, kerosene, sawdust, electric cooker and charcoal). Sawdust has the highest time for the three liter of water to boil. The results to this experiment in descending order are: Sawdust, $38.35 \mathrm{~min}$; charcoal, 33.45 min; kerosene, 25.00min; electric cooker, $23.00 \mathrm{~min}$; gas cooker 25.28min; and palm kernel shell stove, $2.30 \mathrm{~min}$. This experiment shows that palm kernel fueled stove is the fastest due to its short time of $2.30 \mathrm{~min}$ followed by gas fueled stove of time $15.28 \mathrm{~min}$.

Figure 3 shows the fuel performance chart.

\section{Conclusions}

The design and fabrication of the Palm kernel shell stove has been achieved successfully as well as performance evaluation on the stove. Its performance evaluation was carried out by comparing the developed stove with other stoves fueled by sawdust, charcoal, gas, kerosene and electric cooker, and it was discovered it got the shortest time for boiling 3 liters of water in 2.30 minutes. The kernel shells are always available in bag which can last for several months with only five hundred naira ( 500) which are equivalent in dollar rate to more than one US dollar (US\$1.43) compared with the cost of other fuels.

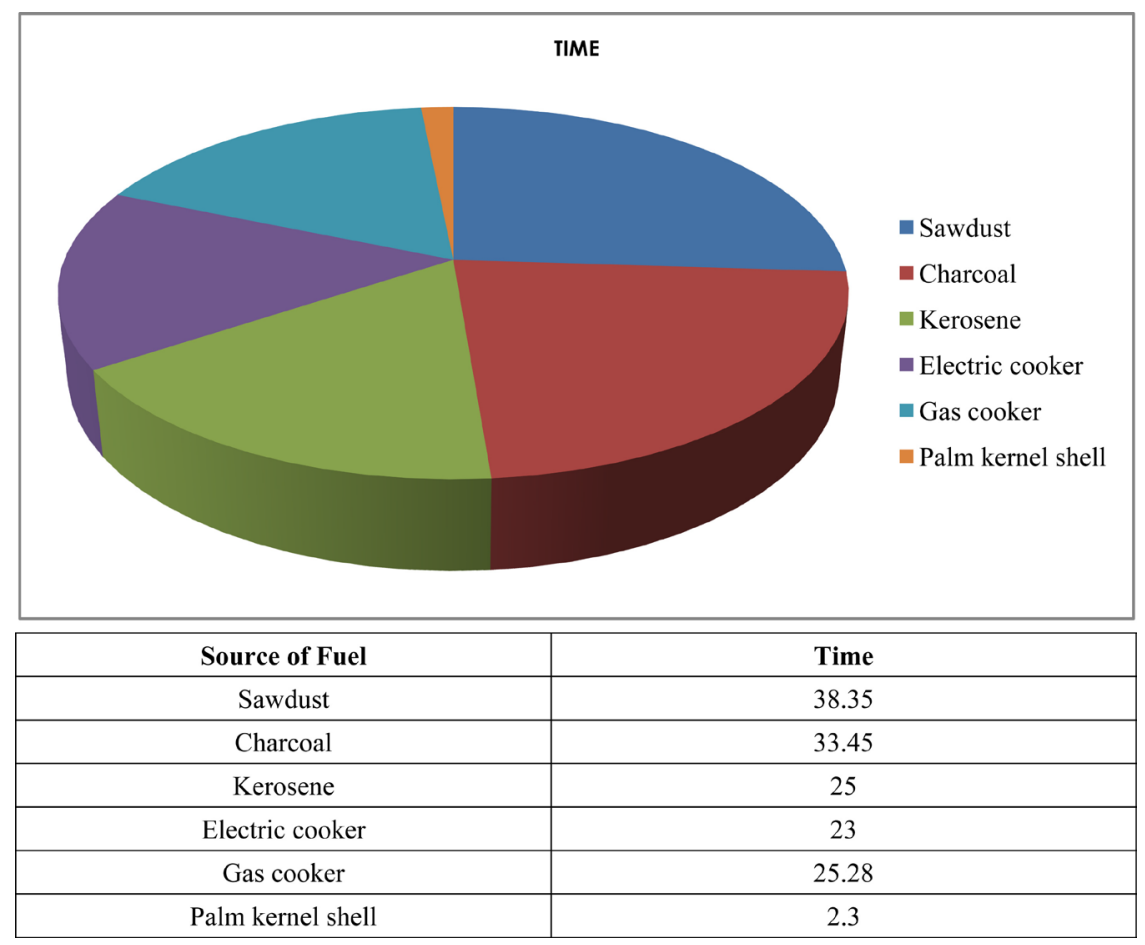

Figure 3. Performance evaluation results on a pie chart. 
Palm kernel shells are attractive renewable energy resource that has been utilized in agricultural industries as a secondary energy source. Due to certain physical characteristics, palm shells are a relatively hard-to-burn biomass fuel, and the combustion chamber design as well as the combustion process should be optimized to enhance combustion efficiency.

\section{Conflicts of Interest}

The authors declare no conflicts of interest regarding the publication of this paper.

\section{References}

[1] Jekayinfa, S. and Bamigboye, A.I. (2008) Energy Used Analysis of Selected Palm Kernel Oil Mill in South Western Nigeria. Journal of Energy, 33, 81-90. https://doi.org/10.1016/j.energy.2007.08.008

[2] Al-Kayiem, H.H. and Yunus, Y.Md. (2013) Drying of Empty Fruit Bunches as Wasted Biomass by Hybrid Solar-Thermal Drying Technique. Journal of Mechanical Engineering and Sciences, 5, 652-661. https://doi.org/10.15282/jmes.5.2013.12.0063

[3] Council for Renewable Energy (CREN) (2012) Nigeria Electricity Crunch. http://www.reneablenigeria.org

[4] Noor, M.M., Wandel, A.P. and Yusaf, T. (2013) Design and Development of MILD Combustion Burner. Journal of Mechanical Engineering and Sciences, 5, 662-676. ttps://doi.org/10.15282/jmes.5.2013.13.0064

[5] Famuyide, O.O., Adebayo, O., Bolaji-Olutunji, K.A., Awe, F., Owoeye, A.Y., Awodele, D.O. and Adeyemo, A. (2013) Assessment and Sustainable Management of Non-timber Forest Products Used as Food and Medicine among Urban Dwellers in Oyo State, Nigeria. Global Science Research Journals, 5, 186-193.

[6] Sunday, O. (2012) Energy and Sustainable Development in Nigeria: The Way Forward. Journal of Energy Sustainability and Society, 2, 15. https://doi.org/10.1186/2192-0567-2-15

[7] Ghobadian, B., Najafi, G. and Nayebi, M. (2013) A Semi-Empirical Model to Predict Diesel Engine Combustion Parameters. Journal of Mechanical Engineering and Sciences, 4, 373-382. https://doi.org/10.15282/jmes.4.2013.2.0035

[8] Noor, M.M., Wandel, A.P. and Yusaf, T. (2014) The Simulation of Biogas Combustion in a Mild Burner. Journal of Mechanical Engineering and Sciences, 6, 995-1013. https://doi.org/10.15282/jmes.6.2014.27.0097

[9] PhanBinh, M.Q., Duong Long, T., Nguyen Viet, D., Tran Trong, B., Nguyen My, HH., Nguyen Luong, H., Nguyen Duc, A. and LuuLoc, C. (2014) Evaluation of the Production Potential of Bio-Oil from Vietnamese Biomass Resources by Fast Pyrolysis. Biomass and Bioenergy, 62, 74-81. https://doi.org/10.1016/j.biombioe.2014.01.012

[10] Hassan, M.B.H. (2012) A Review on Electricity Generation Based on Biomass Residue in Malaysia. Renewable and Sustainable Energy Reviews, 16, 5879-5889. https://doi.org/10.1016/j.rser.2012.06.031

[11] Petr, P. and Vladimír, H. (2018) Economic Analysis of Diesel-Fuel Replacement by Crude Palm Oil in Indonesian Power Plants. Energies, 11, 504.

https://doi.org/10.3390/en11030504 
[12] Bridgwater, A.V. (2012) Review of Fast Pyrolysis of Biomass and Product Upgrading. Biomass and Bioenergy, 38, 68-94.

https://doi.org/10.1016/j.biombioe.2011.01.048

[13] Gharehghani, A., Hosseini, R. and Yusaf, T. (2013) Investigation of the Effect of Additives to Natural Gas on Heavy-Duty Is Engine Combustion Characteristics. Journal of Mechanical Engineering and Sciences, 5, 677-687. https://doi.org/10.15282/jmes.5.2013.14.0065

[14] Ibrahim, M.F., Aziz, S.A., Razak, M.N.A., Phang, L.Y. and Hassan, M.A. (2012) Oil Palm Empty Fruit Bunch as Alternative Substrate for Acetone-Butanol-Ethanol Production by Clostridium Butyricum EB6. Applied Biochemistry and Biotechnology, 166, 1615-1625. https://doi.org/10.1007/s12010-012-9538-6

[15] Agbro, E.B. and Nosa, A. (2013) A Comprehensive Review of Biomass Resources and Biofuel Production Potential in Nigeria. Research Journal in Engineering and Applied Science, 13, 149-155.

[16] Simonyan, K.J. and Fasina, O. (2013) Biomass Resources and Bioenergy Potentials in Nigeria. Renewable and Sustainable Energy Reviews, 8, 4975-4989.

[17] Luangkiattikhun, P., Tangsathitkulchai, C. and Tangsathitkulchai, M. (2008) Non-Isothermal Thermo-Gravimetric Analysis of Oil-Palm Solid Wastes. Bioresource Technology, 99, 986-997. 


\section{Appendices}

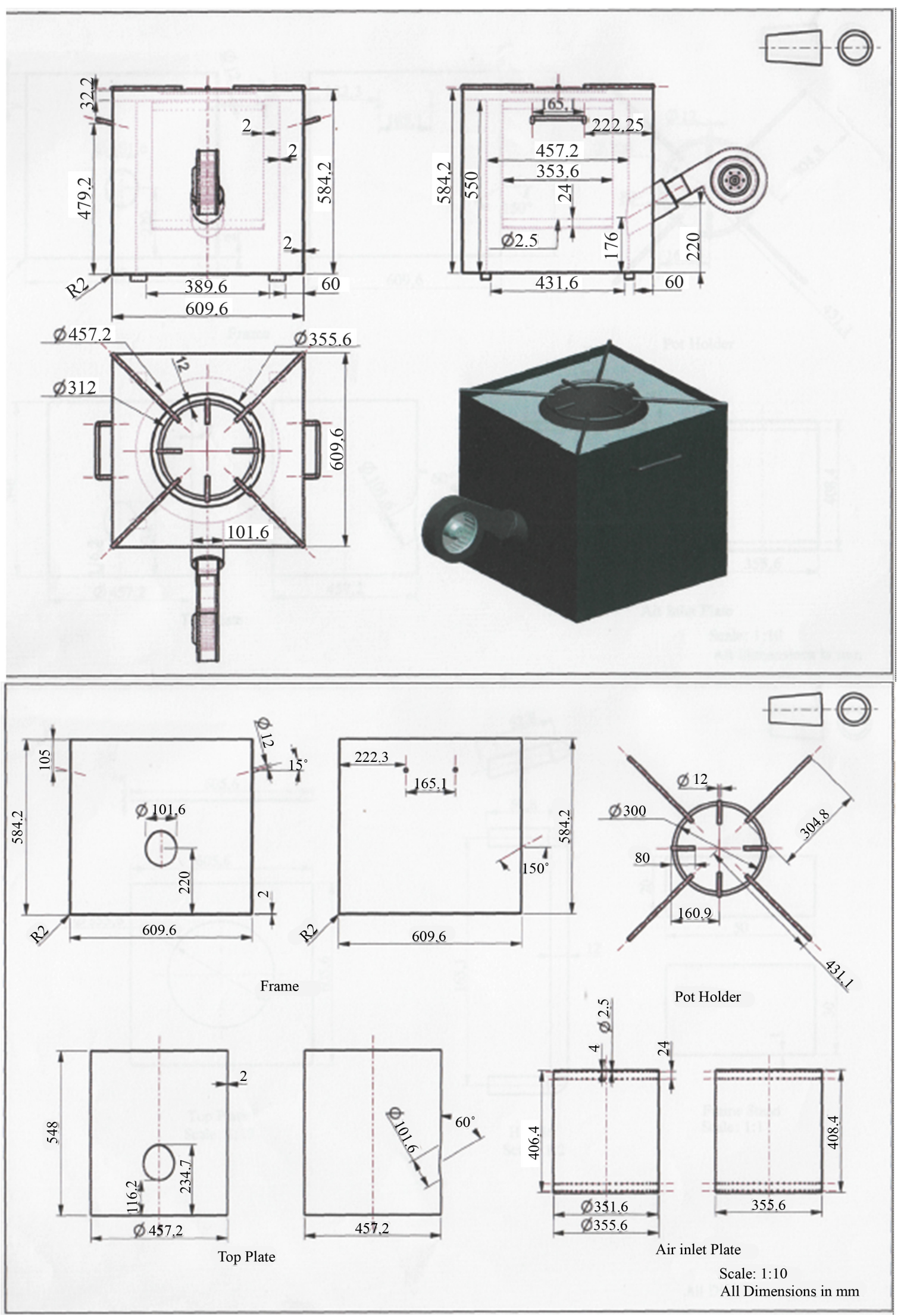




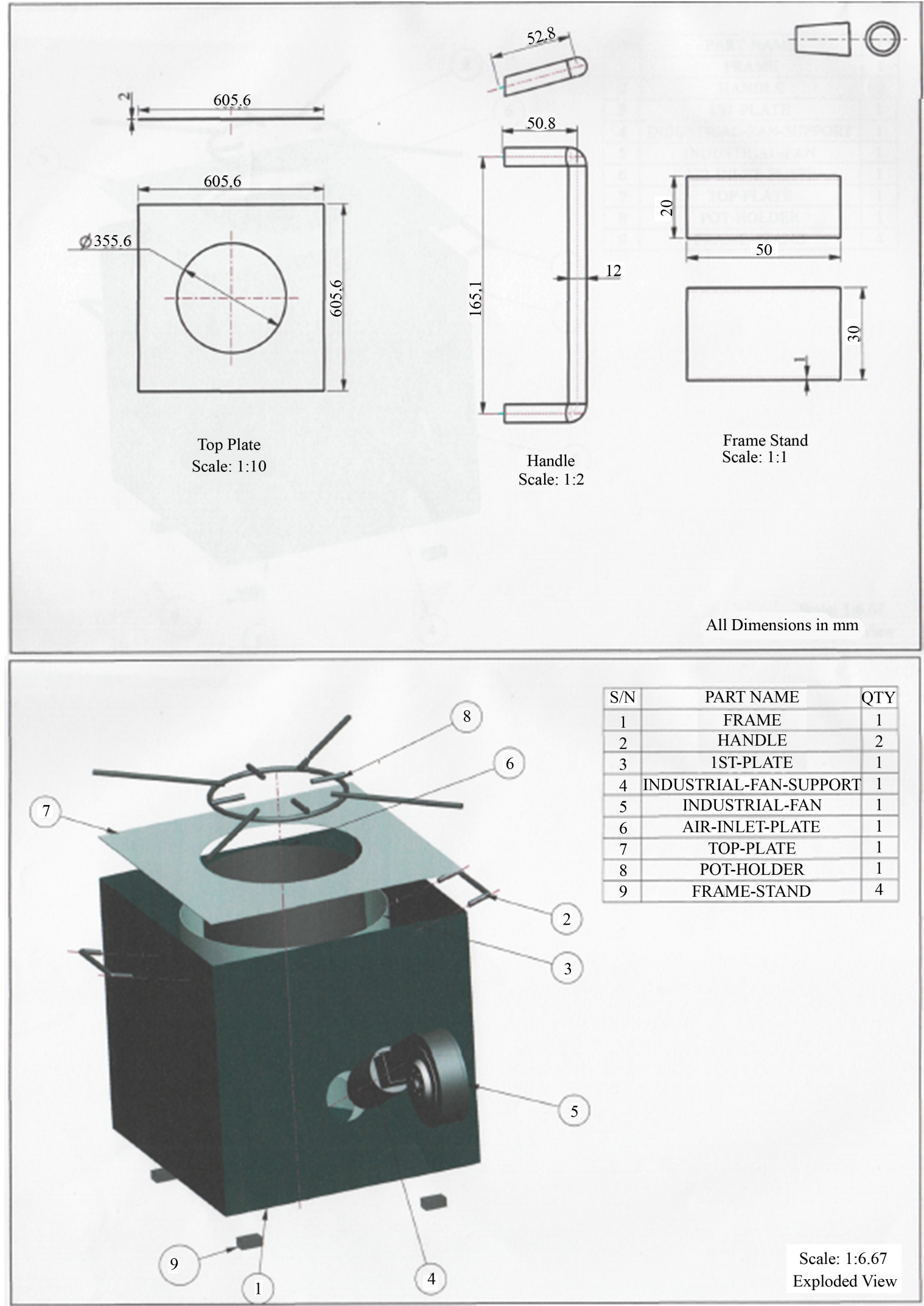

